\title{
Non-fatal head injury among Scottish young people: the importance of assault
}

\author{
Helen MacCallum, Anita Morrison, David H Stone, Keith Murray
}

Department of Clinical Pharmacology, University of Edinburgh, Western General Hospital, Edinburgh

H MacCallum

Paediatric Epidemiology and Community Health (PEACH) Unit, Department of Child Health, University of Glasgow, Royal Hospital for Sick Children, Glasgow A Morrison

D Stone

Department of Public Health, University of Glasgow, Glasgow K Murray

Correspondence to: Dr D Stone, Paediatric Epidemiology and Community Health (PEACH) Unit, Department of Child Health, University of Glasgow, Royal Hospital for Sick Children, Yorkhill, Glasgow G3 8JS

Accepted for publication 16 July 1999
Head injury is a major cause of death and severe disability. ${ }^{12}$ In the UK, mortality attributable to head injury was estimated at $7 / 100000$ in 1994 , with most estimates of age specific hospital admission rates attributable to head injury ranging between 200-300/100 000. ${ }^{2}$ Children and young people seem to be at greatest relative risk. A peak in the age specific incidence of fatal or hospitalised head injury rates is observed in young adulthood (15-30 years) and a peak in accident and emergency presentations attributable to head injury is observed in children under 10 years. ${ }^{3}$

Motor vehicle occupant injuries, pedestrian and cyclist injuries, falls and assaults are frequently cited as the major causes of head injury. However, the proportion of head injuries caused by these specific injury causes varies markedly between countries. ${ }^{1}$ The aim of this study was to determine the incidence of head injury hospitalisation attributable to assault and other injury mechanisms in young Scottish adults aged 15-34 years, with specific emphasis on gender and socioeconomic differentials.

\section{Method}

National routine data on non-fatal hospital discharges with a main diagnosis of head injury were obtained in an anonymised form for Scottish residents aged 15-34 years for the period 1990-1994. All discharges with the primary diagnosis coded as head injury were included. Non-fatal head injuries were detected under several causal categories; road traffic accidents (including pedestrian accidents) (ICD codes 8100-8259), falls (ICD codes 8331-8359, 8800-8889 and 91029109), "strikes" (ICD 9169-9289), assaults and fights (9600-9699) and "other" (ICD 8041-8079, 8260-8329, 8362-8799, 89029069, 9290-9589, 9709-9969). These data were obtained from the Information and Statistics Division, Common Services Agency of the Scottish Health Service. The data were linked to exclude repeat discharges with a sin- gle episode of hospitalisation. Mid-year population estimates were obtained from the Registrar General for Scotland to allow the calculation of hospital discharge rates. Socioeconomic status was measured using the Carstairs-Morris Deprivation Categories, based on characteristics of Scottish postcode sectors. ${ }^{4}$ A continuous scale of $1-7$ is used, where 1 is most affluent, and 7 is most deprived. The level of statistical significance for the calculation of confidence intervals was set at $95 \% . \chi^{2}$ Tests were used to test for differences between groups.

\section{Results}

A total of 35377 young people aged 15-34 years were discharged from hospital after sustaining a head injury between 1990-1994. An $8 \%$ decline in hospitalisation rates was observed over the study period, decreasing from 489/100 000 (CI 477-499) in 1990 to $447 / 100000$ (CI 438-459) in 1994. Men sustained a disproportionate number of head injuries $(28611 ; 81 \%)$. Head injuries were most commonly caused by assaults $(40 \%)$, followed by falls $(23 \%)$, strikes $(19 \%)$, road traffic accidents $(12 \%)$, pedestrian accidents $(2 \%)$, and "other" causes (3\%).

Assault was the commonest cause of head injury hospitalisation in men at all ages, and in women after 20 years of age (table 1). Falls were a commoner cause of head injury hospitalisation than assault among women aged $15-19$ years $(30 \%)$. Men had consistently and significantly higher rates of hospital discharge resulting from assault than women at all ages $(p<0.01)$.

Rates of discharge attributable to assault increased with increasing deprivation score for both men and women $(\mathrm{p}<0.01)$. This pattern was repeated at all ages. Men in deprivation category 7 experienced rates of hospital discharge four times higher than men in deprivation category 1 . Similarly, women in deprivation category 7 experienced rates of hospital discharge six times higher than women in deprivation category $1(\mathrm{p}<0.01)$.

Table 1 Number and percentage of all head injury discharges, number and percentage of all head injury discharges attributable to assault and average annual hospital discharge (AAHD) rate per 1000 population for head injuries attributable to assault

\begin{tabular}{|c|c|c|c|c|c|c|c|c|c|}
\hline \multirow[b]{2}{*}{ Age } & \multicolumn{3}{|l|}{ Men } & \multicolumn{3}{|l|}{ Women } & \multicolumn{3}{|l|}{ Total } \\
\hline & $\begin{array}{l}\text { No of head } \\
\text { injuries (\%) }\end{array}$ & $\begin{array}{l}\text { No of head injuries } \\
\text { attributable to assault } \\
(\%)\end{array}$ & $\begin{array}{l}\text { AAHD rate } \\
\text { per } 1000\end{array}$ & $\begin{array}{l}\text { No of head } \\
\text { injuries (\%) }\end{array}$ & $\begin{array}{l}\text { No of head injuries } \\
\text { attributable to assault } \\
(\%)\end{array}$ & $\begin{array}{l}\text { AAHD rate } \\
\text { per } 1000\end{array}$ & $\begin{array}{l}\text { No of head } \\
\text { injuries (\%) }\end{array}$ & $\begin{array}{l}\text { No of head injuries } \\
\text { attributable to assault } \\
(\%)\end{array}$ & $\begin{array}{l}\text { AAHD rate } \\
\text { per } 1000\end{array}$ \\
\hline $15-19$ & $8065(100)$ & $3278(41)$ & 3.9 & $2122(100)$ & $461(22)$ & 0.6 & $10187(100)$ & 3739 (37) & 2.3 \\
\hline $20-24$ & $8537(100)$ & $3929(46)$ & 3.8 & $1830(100)$ & $504(28)$ & 0.5 & $10367(100)$ & $4433(43)$ & 2.2 \\
\hline $25-29$ & $6921(100)$ & $3026(44)$ & 2.9 & $1518(100)$ & 495 (33) & 0.5 & $8439(100)$ & $3521(42)$ & 1.7 \\
\hline $30-34$ & $5088(100)$ & $2134(42)$ & 2.1 & $1296(100)$ & $415(32)$ & 0.4 & $6384(100)$ & $2549(40)$ & 1.3 \\
\hline Total & $28611(100)$ & $12367(43)$ & 3.2 & $6766(100)$ & $1875(28)$ & 0.5 & $35377(100)$ & $14242(40)$ & 1.8 \\
\hline
\end{tabular}




\section{Discussion}

If hospitalisations reflect incidence, assault is the major cause of head injury among young people in Scotland. Assaults accounted for $40 \%$ of all hospitalisations due to head injury in this age group between 1990-1994. Rates of hospitalisation were particularly high among young men compared with young women. Young people of both sexes residing in areas of relatively greater deprivation had rates of hospitalisation significantly higher than those living in more affluent areas.

There are problems associated with the exclusive reliance on hospital discharge data. These include the distorting effect of excluding fatal and minor injuries, the influence of hospital admission policies on the sociodemographic characteristics of inpatients, and the unknown extent of diagnostic misclassification. These data are, however, the most comprehensive available on head injury in Scotland. While routine surveillance of intentional injuries at accident and emergency departments in the $\mathrm{UK}$ is advocated to provided data on violence related injuries, these systems are rare. ${ }^{5}$

Alcohol use is well documented as a contributory factor in assaults. ${ }^{6-8}$ However, the routine data sources used in this study do not provide sufficient detail on the injury event to elicit the extent of alcohol use among assault victims or their assailants. A recent prospective study of Accident and Emergency patients in Scotland suggests that alcohol had been consumed by over two thirds of assault victims in the six hours before the attack. ${ }^{6}$ Over $90 \%$ of assailants and $80 \%$ of victims were men (mean age 28 years). Similarly, a UK survey of facial injuries showed that over half of assaults were related to alcohol consumption. ${ }^{7}$ In Western Australia, a significant association was found between night time assaults and alcohol consumption. ${ }^{8}$

In summary, these data indicate that assault is the commonest cause of head injury hospitalisation in Scottish young people, with men residing in socially deprived areas at particularly high risk. The underlying explanations and possible contributing factors (including alcohol) require further investigation to plan, formulate and evaluate appropriate preventive responses.

We are grateful to Jack Vize at the Information and Statistics Division of the Scottish Health Service for providing the data. Thanks also go to Harper Gilmour at the Department of Public Health, University of Glasgow for statistical advice.

Conflicts of interest: none.

1 Jennett B, MacMillan R. Epidemiology of head injury. BMf 1981;282:101-4.

2 Jennett B. Epidemiology of head injury. $\mathcal{F}$ Neurol Neurosurg Psychiatry 1996;60:302-6.

3 Brookes M, MacMillan R, Cully S, et al. Head injuries in accident and emergency departments. How different are accident and emergency departments. How different are
children from adults? $\mathcal{F}$ Epidemiol Community Health 1990: 44:147-51.

4 McLoone P. Carstairs scores for Scottish postcode sectors from the 1991 census. Glasgow: University of Glasgow, Public Health Research Unit, 1992.

5 Shepherd JP. Tackling violence. Interagency procedures and injury surveillance are urgently needed. BMF 1998;316: 879. 6 Wright J, Kariya A. Assault patients attending a Scottish 1997;90:322-6.

7 Hutchison IL, Magennis P, Shepherd JP, et al. The BAOMS United Kingdom Survey of Facial Injuries Part 1: Aetiology and the association with alcohol consumption. $\mathrm{Br}$ f Oral Maxillofac Surg 1998;36:3-13.

8 Midford R, Master L, Phillips M, et al. Alcohol consumption and injury in Western Australia: A spatial correlation tion and injury in Western Australia: A spatial correlation
analysis using geographical information systems. Aust NZ $\mathcal{F}$ analysis using geographical in
Public Health 1998;22:80-5. 